\title{
Sexual and aggressive interactions in a mixed species group of lobsters Homarus gammarus and $\boldsymbol{H}$. americanus
}

\author{
Gro I. van der Meeren ${ }^{1}$, Arani Chandrapavan ${ }^{2}$, Thomas Breithaupt ${ }^{3, *}$ \\ ${ }^{1}$ Institute of Marine Research, PB 1870 Nordnes, 5817 Bergen, Norway \\ ${ }^{2}$ Tasmanian Aquaculture and Fisheries Institute, University of Tasmania, Nubeena Crescent, Taroona 7053, Tasmania, Australia \\ ${ }^{3}$ University of Hull, Department of Biological Sciences, Hull HU6 7RX, UK
}

\begin{abstract}
The introduction of non-native populations can have dramatic effects on the native fauna as a result of interbreeding and aggressive interference between closely related species. This study investigates if female European lobsters Homarus gammarus would sexually interact and mate with male American lobsters Homarus americanus, recently introduced to Norwegian waters, if given the choice between the heterospecific and a conspecific male. Interactions between a mixed species pair of male lobsters and a single $H$. gammarus female were recorded during 1 wk periods in a large tank provided with 2 shelters. Trials included either dominant $H$. americanus or dominant $H$. gammarus males. The frequency and duration of social interactions such as aggression, shelter visits, shelter sharing, courtship and mating were analysed. Conspecific courtship occurred in 10 trials, and mating, in 5 trials. No sexual interactions occurred between species. H. gammarus females preferred to court and mate with a conspecific male irrespective of its dominance status. In addition, the $H$. americanus males showed no sexual response to the European females. Females visited conspecific male shelters more frequently than heterospecific male shelters. They received longer visits from the conspecific than from the heterospecific male. Conspecific pairs shared shelters more frequently and over longer periods of time than heterospecific pairs. Conspecific shelter sharing often included courtship, while heterospecific interactions were generally of aggressive nature, with lobsters fighting over shelter. The results suggest that European lobsters are able to recognize conspecific mates, perhaps by chemical signals, and that these signals serve as pre-mating barriers preventing hybridisation.
\end{abstract}

KEY WORDS: Species introduction $\cdot$ Interbreeding $\cdot$ Dominance $\cdot$ Behavioural interactions $\cdot \operatorname{Decapod}$ crustaceans

Resale or republication not permitted without written consent of the publisher

\section{INTRODUCTION}

The introduction of organisms into new geographical regions can bring together formerly separated species to create new interactions that may be detrimental to the native species. Evidence from various plant and animal species is accumulating that apart from aggressive competition, predation, or habitat destruction, introduced species may cause extinction of related species by hybridisation and introgression (Rhymer \& Simberloff 1996). Female mate preference for males of other species may even accelerate genetic intro- gression and loss of the 'pure' species as shown for the North American Pecos pupfish (Echelle \& Connor 1989). Hence, behavioural studies testing the potential for interbreeding are important to understand the impact of species introductions on closely related native species (Huxel 1999).

European lobsters Homarus gammarus Linnaeus, 1758 and American lobsters H. americanus Milne Edwards, 1837 are closely related species with small but significant genetic differences (Hedgecock et al. 1977). They have been geographically isolated since the Pleistocene epoch and appear to have only weak repro- 
ductive isolating barriers (Williams 1995). Allopatric populations of closely related species have been suggested to be much less diverged in mate recognition than sympatric species where mate recognition is reinforced (Higgie et al. 2000). In homarid lobster hybrids have been produced by artificial insemination of female European lobsters with spermatophores from American males (Audouin \& Leglise 1972, Hedgecock et al. 1977, Carlberg et al. 1978). Such artificial hybridisation, however, generated infertile male offspring (Talbot et al. 1984). Hybridisation under semi-natural conditions has been reported as a result of isolating pairs of $\mathrm{H}$. gammarus females and $H$. americanus males over an extended period of time, resulting in fertile female and male progeny (Prof. Jiro Kittaka pers. comm.).

The repeated catch of American lobsters Homarus americanus in Nordic waters since 1999 (16 H. americanus caught until 2006, annual statistics of the International Council of the Exploration of the Sea, ICES) has therefore alarmed ecologists and fishery managers due to possible detrimental effects on the European lobster population (van der Meeren et al. 2000, 2006). In a previous study conducted in a large semi-naturalistic setting, introduced $H$. americanus females and males were found to evict local specimens of weightmatched H. gammarus from their shelters (G. I. van der Meeren, K. O. Ekeli and R. A. Wahle unpubl. data). American lobsters have bigger claws relative to body length compared to European lobsters (see measurements of carapace length versus claw index in van der Meeren \& Uksnoy 2000, Conan et al. 2001, LizarragaCubedo et al. 2003), which may give them an advantage in dominance fights (Scrivener 1971, van der Meeren \& Uksnoy 2000). In the natural environment, the invading American lobsters might dominate the European lobsters and displace them from their habitats. Females of both American and European lobsters prefer to mate with the dominant male and are attracted to the dominant's shelter (Atema \& Voigt 1995, Debuse et al. 1999). If $H$. americanus males are dominant over $H$. gammarus males, females may prefer to mate with dominant males rather than conspecific males and this may lead to interbreeding.

In American lobsters, shelters play a central role in social behaviour (Atema et al. 1979, Karnofsky \& Price 1989, Karnofsky et al. 1989a,b, Cowan \& Atema 1990). Male lobsters establish stable dominance relationships through repeated fights. The dominant male gains access to the best shelter, which is spacious, with small entrance and exit holes. Dominant lobsters frequently check nearby shelters and evict subordinates. The dominant's shelter is frequently visited by other males and by females. While males are repelled, receptive females are allowed to enter the shelter. In the shelter, the female moults and is subsequently mated by the male. After mating the female shares the shelter with the dominant male for up to $2 \mathrm{wk}$, gaining protection during the vulnerable postmoult time.

Chemical signals regulate the social activities of American lobsters. Urine-borne pheromones released during aggressive displays (Breithaupt \& Atema 2000) mediate recognition of the dominant by the subordinate animal (Karavanich \& Atema 1998, Steinbach \& Atema 2004). Urinary chemical signals released by dominant males are attractive to females. Female urinary signals, in turn, communicate information about sex and receptivity to the male (Atema \& Voigt 1995, Bushmann \& Atema 1997). Chemical signal exchange at the entrance to the shelter of the dominant male enables both visiting female and resident male to assess mutual information crucial for their mate choice. Whether these signals also bear species-specific information is not known.

In some species, variation in the chemical communication system can lead to reproductive isolation (Higgie et al. 2000). For instance, studies on insects have revealed that species isolation is maintained or facilitated because pheromones evoke different responses in closely related sympatric species versus conspecifics (Baker et al. 1998). In crustaceans, male dominance status may be recognized by chemical signals shared between species as demonstrated in 2 sympatric species of stomatopods (Caldwell 1982). Whether or not chemical signals can serve as mating barriers in decapod crustaceans still needs to be established. Unfortunately, nothing is known about the role of chemical communication in the social behaviour of European lobsters.

The present study aims to assess the risk of interbreeding between female European lobsters and male American lobsters by investigating behavioural interactions. We concentrate on European females since all hybrids found so far originated from Homarus gammarus females and $H$. americanus males. We hypothesize that due to the separation history of the 2 species, reproductive barriers are not reinforced, leading to little divergence in courtship signals. Hence, females might not be able to discriminate between con- and heterospecific males, and might mate with the dominant male irrespective of its species. Alternatively, there might be strong behavioural barriers, resulting in a preference for conspecific mates.

\section{MATERIALS AND METHODS}

Experimental animals. European lobsters were purchased directly from fishermen at the Yorkshire coast in England (Independent Shellfishermen's Co-operative, Bridlington). Lobsters were selected according to their sex, size and moult stage by the research team at 
the landing facilities at Bridlington. We selected females that were in the last stage preceding moulting (Stage D; Tamm \& Cobb 1978) and intermoult males (Stage C or early Stage D) that were hard shelled and carried encrusting organisms. Only animals with intact appendages and well-developed claws were selected. European lobsters were held in $500 \mathrm{l}$ fibreglass tanks in the laboratory for at least $5 \mathrm{~d}$ prior to being used in the experiment. Within each tank individuals were separated from each other by PVC grids in order to prevent fighting.

Hard-shelled Homarus americanus were imported from Canada (Clearwater Lobster Merchants, London) and shipped from London to Hull in a damp-insulated box provided with ice packs. They were maintained separate from $H$. gammarus in fibreglass tanks for at least 2 wk prior to the experiment, in order to allow them to recover from the stress of transportation. Each fibreglass tank had its own filtering system and protein skimmer. We used natural water from the North Sea transported to the university by a tanker. The lobsters were visually inspected, morphometrically described and moult staged (Aiken 1973, Tamm \& Cobb 1978). At the end of an experiment the female was humanely killed and dissected in order to determine gonad status. Descriptions of the selected experimental lobsters are shown in Table 1.

Laboratory set-up. Two adjacent compartments (Compartment 1, 750 l: $220 \times 100 \times 35 \mathrm{~cm}$; Compartment 2, 860 l: $253 \times 100 \times 35 \mathrm{~cm})$ within a long experimental tank $(473 \times 100 \mathrm{~cm})$ were run simultaneously. The 2 compartments were separated with an opaque dividing wall. There was little water leakage between the compartments through narrow gaps $(0.1$ to $0.2 \times$ $20 \mathrm{~cm}$ ) along each side of the dividing screen. A set of pump, filter and protein skimmer was positioned at each of the opposite ends of the experimental tank, causing the water to circulate horizontally in each compartment independent of each other. Water and air temperature were held stable at $16^{\circ} \mathrm{C} ; 50 \%$ of the water was replaced with fresh seawater every $5 \mathrm{wk}$. The bottoms of the tanks were covered with 3 to $4 \mathrm{~cm}$ deep layers of grey and white garden gravel (3 to $10 \mathrm{~mm}$ pebble width) spread on top of a thin, woven plastic cloth for stabilisation. The side windows of the tanks were covered with black plastic sheets to minimise possible visual disturbances by outside movements. The sheets could be removed for visual inspections.

Two identical concrete shelters (approximately $40 \mathrm{~cm}$ long, $15 \mathrm{~cm}$ high and $25 \mathrm{~cm}$ wide inside) were placed next to the windows, on the long sides of each tank. They had 1 entrance on each end (approximately $9 \mathrm{~cm}$ high and $12 \mathrm{~cm}$ wide), an additional open side towards the tank window and a glass-covered top window $(20 \times 10 \mathrm{~cm})$.
Table 1. Homarus gammarus and H. americanus. Characteristics of lobsters used for the trials. Males from Trials 2 to 8 were re-used in separate trials $(a, b)$ with different females. Claw index was measured in square centimetres and defined by 'mean claw length $\times$ mean claw circumference' (Scrivener 1971). Dominance status of males is: dominant (D) and subordinate $(\mathrm{S})$; gonad status of females is: $0=$ empty; $1=$ very little, compact yolk; 2 = ripening, well-packed oocytes; 3 = large, well-developed oocytes; na = not analysed

\begin{tabular}{|c|c|c|c|}
\hline $\begin{array}{l}\text { Lobster and } \\
\text { trials }\end{array}$ & $\begin{array}{c}\text { Carapace } \\
\text { length (mm) }\end{array}$ & $\begin{array}{l}\text { Claw index } \\
\left(\mathrm{cm}^{2}\right)\end{array}$ & $\begin{array}{l}\text { Dominance or } \\
\text { gonad status }\end{array}$ \\
\hline \multicolumn{4}{|c|}{ Male H. gammarus } \\
\hline 1 & 92.0 & 243 & $\mathrm{D}$ \\
\hline $2 \mathrm{a} ; 2 \mathrm{~b}$ & 89.0 & 239 & $\mathrm{D}$ \\
\hline $3 a ; 3 b$ & 84.7 & 166 & $\mathrm{D}$ \\
\hline $4 \mathrm{a} ; 4 \mathrm{~b}$ & 100.0 & 309 & $\mathrm{D}$ \\
\hline $5 a ; 5 b$ & 90.4 & 269 & $\mathrm{~S}$ \\
\hline $6 a ; 6 b$ & 87.0 & 214 & $\mathrm{~S}$ \\
\hline $7 a ; 7 b$ & 93.0 & 222 & $\mathrm{~S}$ \\
\hline $8 a ; 8 b$ & 82.5 & 159 & na \\
\hline \multicolumn{4}{|c|}{ Male $H$. americanus } \\
\hline 1 & 90.0 & 238 & $\mathrm{~S}$ \\
\hline $2 \mathrm{a} ; 2 \mathrm{~b}$ & 84.9 & 242 & $\mathrm{~S}$ \\
\hline $3 a ; 3 b$ & 86.6 & 242 & S \\
\hline $4 a ; 4 b$ & 86.4 & 270 & S \\
\hline $5 a ; 5 b$ & 95.8 & 354 & $\mathrm{D}$ \\
\hline $6 a ; 6 b$ & 88.6 & 248 & $\mathrm{D}$ \\
\hline $7 \mathrm{a} ; 7 \mathrm{~b}$ & 93.6 & 341 & $\mathrm{D}$ \\
\hline $8 a ; 8 b$ & 83.3 & 200 & na \\
\hline \multicolumn{4}{|c|}{ Female $H$. gammarus } \\
\hline 1 & 88.0 & 144 & 2 \\
\hline $2 \mathrm{a} ; 3 \mathrm{a}$ & 90.0 & 177 & 3 \\
\hline $2 \mathrm{~b}$ & 87.0 & 152 & na \\
\hline $3 b$ & 82.5 & 117 & na \\
\hline $4 \mathrm{a}$ & 85.0 & 131 & na \\
\hline $4 \mathrm{~b}$ & 82.5 & 168 & 2 \\
\hline $5 a$ & 86.5 & 148 & 2 \\
\hline $5 b$ & 83.0 & 132 & 2 \\
\hline $6 a$ & 84.3 & 159 & 2 \\
\hline $6 \mathrm{~b}$ & 84.0 & 154 & 2 \\
\hline $7 a$ & 91.3 & 152 & 0 \\
\hline $7 \mathrm{~b}$ & 95.2 & 163 & 1 \\
\hline $8 a$ & 86.7 & 153 & 2 \\
\hline $8 b$ & 85.0 & 73 & Resorbed \\
\hline
\end{tabular}

Light conditions mimicked the natural conditions around mid-July (16.5 h daylight). Daylight was provided by standard fluorescent tubes and night-time light by $15 \mathrm{~W}$ red bulbs above each tank, providing just sufficient light for video recording. The activity of the lobsters was filmed by a video camera located over each tank (Sony SPT-M320CE, 0.05 lx sensitivity; or Sony SPT-M122CE, $0.1 \mathrm{~lx}$ sensitivity). A time-lapse VTR (SVT-124P, Sony) recorded $24 \mathrm{~h}$ on a $3 \mathrm{~h}$ tape. The recorded video alternated between the 2 cameras every $45 \mathrm{~s}$ (VS-201, Videoswitch), resulting in 50\% time coverage of activity in each tank. For detailed 
analysis, we digitized the recordings to the hard drive of a PC (Digital Video Creator 150, Dazzle).

Behavioural trials. Prior to each trial the dominance between the males was tested in a staged fight. Two claw-size-matched males, 1 Homarus gammarus and $1 \mathrm{H}$. americanus, were put in a 40 by $80 \mathrm{~cm}$ glass aquarium with a dividing wall between them. The wall was removed after lobsters had acclimatized for $15 \mathrm{~min}$, and the interaction between the males was recorded until 1 male showed clear and lasting submission. $H$. gammarus males gained dominance in Trials 1 to 4 , and $H$. americanus, in Trials 5 to 7 (Table 1 ). In Trial 8 no clear dominance was established. After dominance was established, both males were released into the large test tank for at least $15 \mathrm{~h}$ prior to introduction of a female. Following introduction of the female each trial continued until $24 \mathrm{~h}$ after successful mating or, alternatively, for at least $5 \mathrm{~d}$ if no mating had occurred. Except for Trial 1, each pair of males was tested twice with 2 different $H$. gammarus females (Table 1, replicates a and b), resulting in 15 trials of 8 different male pairs and $12 \mathrm{H}$. gammarus females. Three females were re-used in a second experiment with a new pair of males. One of the females was reused in a second experiment since she showed particularly high sexual activity (Trials 2a and 3a). Two females were used prior to and after moulting (Trials $5 \mathrm{a}$ and $7 \mathrm{~b}$, Trials $2 \mathrm{~b}$ and $7 \mathrm{a}$ ).

Behavioural data were analysed with event recording software (Observer Video-Pro 5.0, Noldus Information Technology). Behaviours were scored using a predefined list of behavioural categories (Table 2) aimed at addressing the following questions:

1. Do heterospecific and conspecific pairs differ with respect to the frequency and time of sexual interactions and matings?

2. Do heterospecific and conspecific pairs differ with respect to the frequency and time visiting other shelters or sharing a shelter?

3. Does male dominance affect mating opportunity and success?

4. Are there any species- or sex-related differences with respect to the frequency and duration of pairwise agonistic interactions?

The frequency and duration of sexual behaviours (defined in Atema \& Voigt 1995) were analysed for the first $4 \mathrm{~h}$ immediately following release of the female and during the 2 subsequent $7.5 \mathrm{~h}$ nights. In some cases spermatophore transfer was observed live, as it happened when an observer was present in the study room.

We analysed frequency and duration of agonistic interactions, defined as lobsters interacting physically with each other by claw boxing, striking, or ripping (following the definitions of Atema \& Voigt 1995). The
Table 2. Homarus gammarus and H. americanus. Description of behavioural events scored

\begin{tabular}{|c|c|}
\hline Behavioural event & Description \\
\hline Sheltered & $\begin{array}{l}\text { All or parts of the lobster are situated } \\
\text { inside the shelter }\end{array}$ \\
\hline Out of shelter & $\begin{array}{l}\text { The whole body of the lobster is outside } \\
\text { the designated shelter }\end{array}$ \\
\hline Shelter visit & $\begin{array}{l}\text { A lobster approaches and rests outside } \\
\text { an occupied shelter, touching the } \\
\text { entrance }\end{array}$ \\
\hline Shelter sharing & $\begin{array}{l}\text { Two or } 3 \text { lobsters are in the same shel- } \\
\text { ter at the same time }\end{array}$ \\
\hline Agonistic & $\begin{array}{l}\text { Physical threats and interactions, in- } \\
\text { cluding meral spread, snapping, rip- } \\
\text { ping, pushing, boxing, scissoring, or } \\
\text { claw locking }\end{array}$ \\
\hline Sexual interaction & $\begin{array}{l}\text { Generally starts with } 1 \text { lobster ap- } \\
\text { proaching the other with closed chelae; } \\
\text { includes } 1 \text { or more of the following } \\
\text { behaviours: gently stroking the other } \\
\text { with closed chelae, resting side by side, } \\
\text { male mounting female, dragging (the } \\
\text { male moves alongside the female, } \\
\text { embraces her carapace with } 1 \text { claw and } \\
\text { tries to physically drag her towards a } \\
\text { shelter) male turning female over, } \\
\text { mating (female on her back with } \\
\text { stretched abdomen, male positioned } \\
\text { above female). No confirmation for } \\
\text { spermatophore transfer }\end{array}$ \\
\hline Mating & $\begin{array}{l}\text { As for sexual interaction, but with posi- } \\
\text { tive records of spermatophore transfer } \\
\text { (confirmed by live observation in some } \\
\text { instances) }\end{array}$ \\
\hline Locomotion & Moving forward, backward, or turning \\
\hline Resting & Not moving \\
\hline
\end{tabular}

comparisons of aggressive interactions were based on the night after the release of the female.

Many of these events were not observed continuously from the start to the end, as the video-recording switched every $45 \mathrm{~s}$ between the 2 cameras viewing different compartments. If a behaviour started in an unrecorded interval, we disregarded this interval and only scored from the beginning of the next recorded interval. If it ended in an unrecorded interval, we scored until the end of the last recorded interval.

Statistical analysis. Since data were not normally distributed we used non-parametric statistical tests. For comparing interactions (sexual interactions, shelter sharing, visiting, aggression) we used paired ANOVAs (Friedman ANOVA) and paired comparisons (Wilcoxon signed-rank test) pairing interactions per trial. For these analyses we used a subset of the data excluding Trial 3a (female identical to that in Trial 2a) and 
excluding Trials $7 \mathrm{a}$ and $8 \mathrm{~b}$ in which female gonad status indicates that the females were not receptive. In addition, we used the average of those data in which the same males were used twice in order to prevent pseudo-replications. For non-paired tests we used Mann-Whitney $U$-tests. When using multiple statistical tests probability (p) was denoted after sequential Bonferroni correction (Hochberg 1988).

\section{RESULTS}

\section{Dominance}

American male lobsters Homarus americanus were dominant in 6 out of 15 trials, whereas $H$. gammarus males were dominant in 7 trials (Table 1). In the last 2 trials, neither male was obviously dominant, as both performed dominance displays towards each other.

\section{Sexual interactions}

Sexual interactions and mating occurred in 9 out of 15 trials, all between male and female Homarus gammarus (Table 3). No sexual interactions were observed between $H$. americanus and $H$. gammarus. Hence, the frequency and duration of sexual interactions were higher between conspecific than between heterospecific male-female pairs $(p=0.031$, in both tests; Wilcoxon signed-rank test; see Table 3).

The 5 incidences of mating included 4 Homarus gammarus males and 4 females. One male mated with 2 different females in 2 subsequent trials. One female mated a few days before moulting and then again $48 \mathrm{~h}$ after moulting when exposed to different males. The other 3 females mated in the late premoult stage, with maturing gonads containing densely packed, granulated eggs. All but 1 mating occurred inside a shelter within 25 min after introduction of the female, and was followed by more or less continuous cohabitation of shelter from $23 \mathrm{~min}$ up to $>25 \mathrm{~h}$. During 1 mating event, the $H$. gammarus male in the adjacent tank compartment was visibly aroused (probably by chemi- cal stimulation) trying to climb over the dividing wall, close to the mating shelter. $H$. americanus males never reacted to sexual interactions of a $H$. gammarus pair.

\section{Shelter visits}

Females visited shelters occupied by Homarus gammarus males more frequently $(p=0.027$; Wilcoxon signed-rank test; Fig. 1) and for longer times ( $p=0.019$; Wilcoxon signed-rank test) than those of $H$. americanus males. Male H. gammarus spent significantly more time than $H$. americanus at the entrance of female-occupied shelters ( $p=0.008$; Wilcoxon signedrank test). We found no difference in the time and frequency of shelter visits between European males visiting shelters occupied by an American male and American males visiting a shelter occupied by a European male (Fig. 1).

\section{Shelter sharing}

In all but 3 trials, shelter sharing was observed. Time of shelter sharing differed between different pairings of lobsters $\left(p=0.016\right.$, $d f=2, \chi^{2}=8.3$; Friedman ANOVA for repeated measures; Fig. 2), with Homarus gammarus pairs spending significantly more time together in a shelter than $H$. gammarus males and $H$. americanus males ( $\mathrm{p}=0.048$; Wilcoxon signed-rank test after sequential Bonferroni correction). There was no difference in time of shelter sharing between $H$. gammarus pairs and pairs of a $H$. gammarus female and $H$. americanus male $(\mathrm{p}=0.094$; Wilcoxon signedrank test after sequential Bonferroni correction). Frequency of shelter sharing also differed across groups $\left(\mathrm{p}=0.004, \mathrm{df}=2, \chi^{2}=11.1\right.$; Friedman ANOVA) with male-female $H$. gammarus sharing shelter more frequently than interspecific male-male pairs $(p=0.048$; Wilcoxon signed-rank test). Interactions in the shelter were always of an aggressive nature when both species were involved (Fig. 2A). Interactions in H. gammarus pairs were mostly of a sexual nature, but sometimes included aggression.

Table 3. Homarus gammarus. Summary data of sexual interactions (with and without mating) between H. gammarus males and $H$. gammarus females. Data for frequency and duration of sexual interactions are also presented. No sexual interactions were observed between $H$. americanus and $H$. gammarus

\begin{tabular}{|lcccc|}
\hline Male behavioural type & $\begin{array}{c}\text { Trials } \\
\text { with mating (n) }\end{array}$ & $\begin{array}{c}\text { Trials } \\
\text { without mating (n) }\end{array}$ & $\begin{array}{c}\text { Frequency } \\
\text { (mean } \pm \text { SE) }\end{array}$ & $\begin{array}{c}\text { Duration (s) } \\
(\text { mean } \pm \text { SE) }\end{array}$ \\
\hline Dominant & 2 & 3 & $8 \pm 4$ & $515 \pm 281$ \\
Subordinate & 3 & 1 & $5.3 \pm 2.3$ & $730 \pm 388$ \\
\hline
\end{tabular}



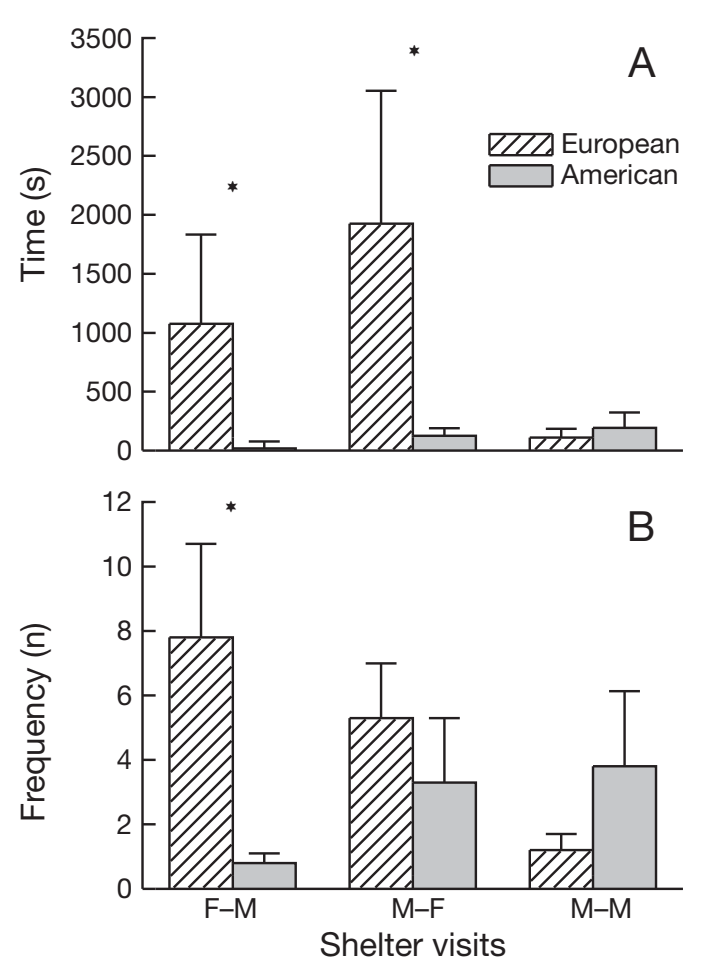

Fig. 1. Homarus gammarus and H. americanus. (A) Average duration and (B) frequency of shelter visits per trial (mean + $\mathrm{SE}$ ) of a $H$. gammarus female visiting a $H$. gammarus or $H$. americanus male $(\mathrm{F}-\mathrm{M})$ and of a $H$. gammarus or $H$. americanus male visiting a female $(\mathrm{M}-\mathrm{F})$ or another male (M-M). Hatched columns refer to male $H$. gammarus visiting or being visited; grey columns refer to male $H$. americanus. For male-male interactions, hatched columns denote visiting $H$. gammarus males and grey columns denote visiting $H$. americanus males. *significant difference within each group between hatched and grey columns $(p<0.05$; Wilcoxon signedrank tests)

\section{Effect of male dominance}

Male dominance did not appear to have an effect on the duration of shelter sharing with a female or on the frequency and duration of sexual interactions. The time females spent in the shelter with subordinate male Homarus gammarus (mean $\pm \mathrm{SE}$ : $118.2 \pm 66.6$ min; $\mathrm{n}=6$ trials) did not differ from the time they spent with dominant male H. gammarus (mean \pm SE: $24.2 \pm 9.4$ min, $\mathrm{n}=$ 7 trials, $\mathrm{p}=0.23, U=30$ Mann-Whitney $U$-test).

Both dominant $(\mathrm{n}=2)$ and subordinate Homarus gammarus males $(\mathrm{n}=3$ ) had sexual interactions and mated with females (Table 3 ). Prolonged sexual interactions, lasting for $>3 \mathrm{~min}$, were registered in 5 trials with dominant $H$. gammarus and in 4 trials with subordinate $H$. gammarus males. There was no difference in the frequency and duration of sexual interaction between dominant and subordinate lobsters $(\mathrm{p}=0.4$, $U=14.5$, Mann-Whitney $U$-test; $\mathrm{p}=0.95, U=20$, Mann-Whitney $U$-test, respectively).



Fig. 2. Homarus gammarus and H. americanus. (A) Average duration and (B) frequency of shelter sharing per trial (mean + SE) between a H. gammarus male and a H. gammarus female (MHG+FHG), a $H$. americanus male and a $H$. gammarus female (MHG+FHG), and a $\mathrm{H}$. americanus male and a H. gammarus male (MHA+MHG). In Panel (A) hatched columns refer to time involved in aggressive interaction and grey columns refer to total time. * significant difference between the pairs MHG+FHG and MHA+MHG ( $p<0.05$; Wilcoxon signed-rank tests)

\section{Aggressive interactions}

Most male pairs had established their dominance relationship in the boxing match prior to their release into the experimental tank. Physical aggressions in the test tank were rare and of short duration. The dominant male did use threat displays. In 4 trials, the subordinate male did not inhabit a shelter, but was hiding in a corner or other narrow, partly open location. One dominant male did the same for the first $3 d$, but was found in a shelter from Day 4 onwards. After introduction, the female was active in exploring the tank and approached the males repeatedly. This resulted in an increase in female-male aggressive interactions. In the $4 \mathrm{~h}$ after the introduction of the female, we found differences in the time of aggressive interactions ( $\mathrm{p}=$ 0.044, df $=2, \chi^{2}=6.3$; Friedman ANOVA; Fig. 3), but not in the frequency of aggression across pairs ( $\mathrm{p}=$ 0.08, df $=2, \chi^{2}=5.1$; Friedman ANOVA). Conspecific European lobster pairs spent a longer time in aggres- 

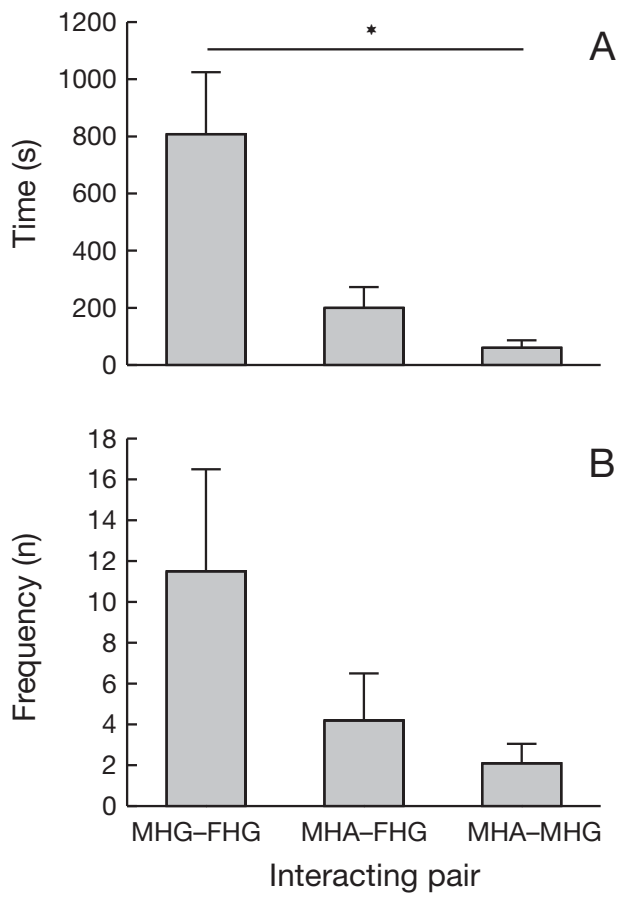

Fig. 3. Homarus gammarus and H. americanus. (A) Average time and (B) frequency of aggressive interactions per trial in the $4 \mathrm{~h}$ after introduction of the female (mean $+\mathrm{SE}$ ). MHG: male $H$. gammarus; FHG: female $H$. gammarus; MHA: male $H$. americanus. ${ }^{*}$ significant difference between groups $(\mathrm{p}<0.05$; Friedman ANOVA)

sive interactions than interspecific male pairs $(\mathrm{p}=$ 0.048; Wilcoxon signed-rank test after sequential Bonferroni correction), but did not differ in aggression time from interspecific male-female pairs $(p=0.1$; Wilcoxon signed-rank test after sequential Bonferroni correction). The female evicted subordinate males from their shelters in 3 trials. In 1 case, the dominant Homarus americanus male left his shelter to the very aggressive female and went on to evict the subordinate H. gammarus male from the other shelter.

Neither the frequency of aggressive incidences nor the total aggression time was different across any of the combinations of pairs in the 2 subsequent nights after the release of the female (frequency: $\mathrm{p}=0.21$, $\mathrm{df}=2, \chi^{2}=3.1$; Friedman ANOVA; time: $\mathrm{p}=0.23$, $\mathrm{df}=2, \chi^{2}=3.0$; Friedman ANOVA).

\section{DISCUSSION}

The present study indicates that during the breeding season female Homarus gammarus, when given the choice between male $H$. gammarus and $H$. americanus, show a clear preference for the conspecific male even when this individual was subordinate to the he- terospecific male. Sexual interactions, including mating, occurred only between European males and females and never between European females and American males. Females were attracted more to the conspecific $H$. gammarus male than to the $H$. americanus male. They visited more frequently (Fig. 1) and shared shelter more often and for longer time periods with the conspecific male than with the heterospecific male (Fig. 2). Conspecific males were likewise attracted by the female, indicated by the long duration of their visits with females and their reduced aggression when sharing shelter with the female (Fig. 2). The male $H$. americanus did not appear to discriminate between heterospecific males and females. The frequency and duration of visits to shelters occupied by males and females did not differ (Fig. 1). Similarly, American males did not reside more frequently or longer in the same shelter with a female than with a heterospecific male. They were equally aggressive toward male and female heterospecifics (Figs. 2 \& 3).

It is a possibility that reduced sexual activity in Homarus americanus could have been caused by the longer handling time due to the distance it had to be transported. However, American lobsters were given a longer acclimation time in the laboratory to recover from transport. American lobsters were held for at least 2 wk in our aquaria before being used in the trials, while European lobsters had at least $4 \mathrm{~d}$ of acclimation time. The selected males were all alert and vigorously attacked the person picking them up for measurements and trials. $H$. americanus males were also able to win dominance fights in 3 out of 8 male contests. Additionally, they were found to be active in aggressive interactions and shelter fights during the trials. Therefore, it seems very unlikely that transportation fatigue was responsible for the lack of sexual activity in the American lobster.

Homarus americanus studies have shown that females prefer dominant males when given a choice. When there is no choice they accept any reasonably sized male (Atema \& Voigt 1995, Debuse et al. 1999). That makes the present study even more poignant: here, the $H$. gammarus females preferred conspecific males regardless of their dominance status in relation to the $H$. americanus male. In fact, most of the prolonged interactions occurred between $H$. gammarus subordinate males and females. Clearly, H. gammarus females prefer even subordinate $H$. gammarus males to $H$. americanus males.

The results suggest the existence of pre-mating reproductive barriers between the 2 homarid species. Temporal barriers can be excluded as the 2 species are similar with respect to their reproductive period and daily cycles of activity (Cooper \& Uzmann 1980, Karnofsky \& Price 1989, Smith et al. 1998). Behavioural 
barriers may be due to differences in the courtship behaviour or difference in courtship signals (mate recognition). Courtship appears to follow the same pattern in the 2 species, including a period of cohabitation and mating inside a shelter (Cooper \& Uzmann 1980, Atema \& Voigt 1995, Debuse et al. 1999, 2003, Gosselin et al. 2003). We observed cohabitation in pairs of Homarus gammarus only. It appeared in 4 out of 5 trials that included mating. It started with the approaching lobsters (either male or female) entering the shelter with closed chelae in a low position, or with the tail first, without eliciting aggressive behaviour in the resident lobster. Unexpectedly, and in contrast to typical American lobster mating behaviour, European female lobsters did not moult prior to mating in our study, although 9 of the 15 females were in the last premoult stage (Stage D; Tamm \& Cobb 1978). Other studies of European lobster sexual behaviour did not report whether mating was hard shelled (intermoult mating) or soft shelled (postmoult mating; Debuse et al. 1999, 2003).

Intermoult mating is curious as it results in sperm loss at moulting and the need to re-mate after moulting. This has been seen occasionally also in Homarus americanus (Dunham \& Skinner-Jacobs 1978). Recent laboratory experiments resulted in postmoult matings in some $H$. gammarus pairs and intermoult mating in other H. gammarus pairs (M. Skog, University of Lund, pers. comm.). Therefore, a difference in the moult cycle of females during mating may not be pronounced and cannot explain the absence of interspecific courtship behaviour in our study.

The most parsimonious explanation for conspecific preference of European lobsters is species recognition. Most modes of reproductive isolation involve some component of sensory recognition (Palumbi 1994). In many cases, species recognition is mediated by the same signals that are used to assess mates (Ryan \& Rand 1993). Stomatopods, amphipods and isopods have been shown to use complex behavioural mechanisms including chemical communication that may isolate sibling species (Palumbi 1994). In lobsters, chemical signals have been shown to play a crucial role in mating behaviour. Female American lobsters are chemically attracted from a distance to the males' shelters (Bushmann \& Atema 1997, 2000). American lobster females were only attracted to and mated with males that released urinary chemical signals. However, females did not discriminate from a distance between dominant and subordinate males (Bushmann \& Atema 2000). In our study, female European lobsters may have recognized species of a potential mating partner based on chemical signals. Females visited conspecific males longer and more frequently than heterospecific males (Fig. 1). Males, in turn, spent more time near conspecific female shelters than near heterospecific male shelters, suggesting that they recognized the nearby female as a potential mate. Male American lobsters increase urine release in response to a female entering the shelter, enabling the female to chemically assess the male (Bushmann \& Atema 2000). American male lobsters do not recognize mates from a distance (Bushmann \& Atema 1997). However, they spend much time trying to enter female shelters but not male shelters. Blocking female urine release increases male aggression toward her, suggesting that females are recognized by males through chemical signals once nearby (Bushmann \& Atema 1997). When American lobsters cohabitate they release chemical signals that attract other males and females to the mating shelter (Atema \& Voigt 1995). In our study, 1 male Homarus gammarus from the neighbouring compartment was strongly aroused when conspecific mating occurred behind the separating partition close to the mating shelter. In the absence of visual information from the neighbouring compartment (due to the opaque dividing wall) these strong responses were most probably mediated by chemical signals conveyed by water leaking through the narrow gaps between the compartments. The heterospecific male in the same compartment never reacted to courtship or mating behaviour. $H$. americanus males never appeared to recognize $H$. gammarus females as potential mates.

The ranges of Homarus gammarus and $H$. americanus are separated by geographic boundaries set by the North Atlantic Gulf Stream. Gene flow across the Atlantic is limited by larval dispersal over such long distances (Palumbi 1994). Work on species separated by the Isthmus of Panama has shown that reproductive isolation at the recognition level can arise without contact between newly formed species (Knowlton et al. 1993). It has been suggested that the 2 homarid species were isolated during the Pleistocene and evolved allopatrically (Williams 1995). There are significant genetic variations between the 2 species (Hedgecock et al. 1977, Ferguson 2002). Eggs of a H. americanus female cannot be fertilized by the sperm of a H. gammarus male (Hedgecock et al. 1977, Carlberg et al. 1978). The relationship is close enough to result in crossbreeding and fertile offspring in the laboratory, when a male $H$. americanus is left alone with a receptive female $H$. gammarus for an extended time period (Prof. J. Kittaka pers. comm.). Our study suggests that in homarid lobsters, species recognition is one crucial mechanism to maintain reproductive barriers. Although female European lobsters have a preference for conspecific males, they may be less discriminating when no conspecific male is present. However, due to the strong behavioural preference for conspecific mates, as documented in the present study, large-scale 
introgression by hybridisation leading to rapid genetic extinction of the native $H$. gammarus is unlikely to occur. Small-scale introgression resulting from occasional hybridisation may still have deleterious effects on European lobsters. Should the introgressed alleles bring about selection advantages for the hybrids, they could cause displacement of the native species via genetic assimilation in the long term (Huxel 1999). Further studies are needed to test whether species recognition is based on olfactory signals and under which conditions the mating barriers may break down. Competition for shelter is an additional threat imposed by invading American lobsters. American lobsters with their relatively larger claws were found to evict European lobsters from their shelters (G. I. van der Meeren, K. O. Ekeli and R. A. Wahle unpubl. data). This could lead to local displacement of native European lobsters by invading populations of American lobsters.

Acknowledgements. We thank Drs. J. Atema and J. D. Hardege for help with the experimental design of the study. J. Atema showed us how to manufacture lobster shelters. Thanks also to Dr. A. B. Skiftesvik, Mr. E. Dahl and Dr. I. Mjølnerød Bysveen for their active support to make this collaborative project possible and to Mr. B. Gricar and Drs. J. Atema and $\mathrm{B}$. Haenfling for valuable comments on previous versions of the manuscript. We thank 2 anonymous reviewers for important comments on content and presentation. The study was supported by a NERC fellowship NER/I/S/2000/01411 and a NERC project grant NER/B/S/2002/00375 to T.B. G.I.v.d.M was supported by the Institute of Marine Research Norway and by a travel grant from the Norwegian Directorate for Nature Management.

\section{LITERATURE CITED}

Aiken DE (1973) Proecdysis, setal development, and molt prediction in American lobster (Homarus americanus). J Fish Res Board Can 30:1337-1344

Atema J, Voigt R (1995) Behavior and sensory biology. In: Factor JR (ed) Biology of the lobster Homarus americanus. Academic Press, New York, p 313-348

Atema J, Jacobson S, Karnofsky E, Oleszko-Szuts S, Stein L (1979) Pair formation in the lobster, Homarus americanus: behavioral development, pheromones and mating. Mar Behav Physiol 6:277-296

Audouin J, Leglise M (1972) Premiers resultata d'experiences relatives aux possibilités d'acclimatation de homard américain Homarus americanus en France. ICES Comm Meet E:34:1-3

Baker TC, Fadamiro H, Cossé AA (1998) Moth uses fine tuning for odour resolution. Nature 393:530

Breithaupt T, Atema J (2000) The timing of chemical signaling with urine in dominance fights of male lobsters (Homarus americanus). Behav Ecol Sociobiol 49:67-78

Bushmann PJ, Atema J (1997) Shelter sharing and chemical courtship signals in the lobster, Homarus americanus. Can J Fish Aquat Sci 54:647-656

Bushmann PJ, Atema J (2000) Chemically-mediated mate location and evaluation in the lobster, Homarus americanus. J Chem Ecol 26:883-899

Caldwell RL (1982) Interspecific chemically mediated recog- nition in two competing stomatopods. Mar Behav Physiol 8:189-197

Carlberg JM, van Olst JC, Ford RF (1978) A comparison of larval and juvenile stages of the lobsters, Homarus americanus, Homarus gammarus and their hybrid. Proc World Maric Soc 9:109-122

Conan GY, Comeau M, Moriyasu M (2001) Are morphometrical approaches appropriate to establish size at maturity for male American lobster, Homarus americanus? J Crustac Biol 21:937-947

Cooper RA, Uzmann JR (1980) Ecology of juvenile and adult Homarus. In: Cobb J, Phillips B (eds) The biology and management of lobsters, Vol 2. Academic Press, London, p 97-142

Cowan DF, Atema J (1990) Moult staggering and serial monogamy in American lobsters, Homarus americanus. Anim Behav 39:1199-1206

Debuse VJ, Addison JT, Reynolds JD (1999) The effects of sex ratio on sexual competition in the European lobster. Anim Behav 58:973-981

> Debuse VJ, Addison JT, Reynolds JD (2003) Effects of breeding site density on competition and sexual selection in the European lobster. Behav Ecol 14:396-402

Dunham PW, Skinner-Jacobs D (1978) Intermolt mating in the lobster (Homarus americanus). Mar Behav Physiol 5: 208-214

- Echelle AA, Connor PJ (1989) Rapid, geographically extensive genetic introgression after secondary contact between two pupfish species (Cyprinodon, Cyprinodontidae). Evolution 43:717-727

Ferguson AEA (2002) Genetic diversity in the European lobster (Homarus gammarus): population structure and impacts of stock enhancement. Available at: www.qub.ac. iuk/bb/prodhol/GEL/gel.html

Gosselin T, Sainte-Marie B, Bernatchez L (2003) Patterns of sexual cohabitation and female ejaculate storage in the American lobster (Homarus americanus). Behav Ecol Sociobiol 55:151-160

> Hedgecock D, Nelson K, Simons J, Shleser R (1977) Genic similarity of American and European species of the lobster Homarus. Biol Bull 152:41-50

Higgie M, Chenoweth S, Blows MW (2000) Natural selection and the reinforcement of mate recognition. Science 290: 519-521

> Hochberg Y (1988) A sharper Bonferroni procedure for multiple tests of significance. Biometrika 75:800-802

> Huxel GR (1999) Rapid displacement of native species by invasive species: effects of hybridization. Biol Conserv 89: $143-152$

Karavanich C, Atema J (1998) Olfactory recognition of urine signals in dominance fights between male lobsters, Homarus americanus. Behaviour 135:719-730

Karnofsky EB, Price HJ (1989) Dominance, territoriality and mating in the lobster, Homarus americanus: a mesocosm study. Mar Behav Physiol 15:101-121

Karnofsky EB, Atema J, Elgin RH (1989a) Field observations of social behavior, shelter use, and foraging in the lobster, Homarus americanus. Biol Bull 176:239-246

Karnofsky EB, Atema J, Elgin RH (1989b) Natural dynamics of population structure and habitat use of the lobster, Homarus americanus, in a shallow cove. Biol Bull 176: $247-256$

> Knowlton N, Weigt LA, Solorzano LA, Mills DK, Bermingham E (1993) Divergence in proteins, mitochondrial DNA, and reproductive compatibility across the isthmus of Panama. Science 260:1629-1632

Lizarraga-Cubedo HA, Tuck I, Bailey N, Pierce GJ, Kinnear 
JAM (2003) Comparisons of size at maturity and fecundity of two Scottish populations of the European lobster, Homarus gammarus. Fish Res 65:137-152

Palumbi SR (1994) Genetic divergence, reproductive isolation and marine speciation. Annu Rev Ecol Syst 25:547-572

Rhymer JM, Simberloff D (1996) Extinction by hybridization and introgression. Annu Rev Ecol Syst 27:83-109

Ryan MJ, Rand AS (1993) Species recognition and sexual selection as a unitary problem in animal communication. Evolution 47:647-657

Scrivener JCE (1971) Agonistic behavior of the American lobster Homarus americanus. J Fish Res Board Can Tech Rep 235:1-113

Smith IP, Collins KJ, Jensen AC (1998) Movement and activity patterns of the European lobster, Homarus gammarus, revealed by electromagnetic telemetry. Mar Biol 132: 611-623

Steinbach MA, Atema J (2004) Individual recognition in the lobster, Homarus americanus: the loser remembers. Comp Biochem Physiol A 137:S31

Talbot P, Thaler C, Wilson P (1984) Spawning, egg attach-

Editorial responsibility: Sönke Johnsen,

Durham, North Carolina, USA ment and egg retention in captive lobsters (Homarus americanus). Aquaculture 37:239-249

Tamm GR, Cobb JS (1978) Behavior and crustacean molt cycle-changes in aggression of Homarus americanus. Science 200:79-81

van der Meeren GI, Uksnoy LE (2000) A comparison of claw morphology and dominance between wild and cultivated male European lobster. Aquacult Int 8:77-94

van der Meeren GI, Ekeli KO, Jørstad KE, Tveite S (2000) Americans on the wrong side-the lobster Homarus americanus in Norwegian waters. ICES CM 2000/U:20: $1-15$

van der Meeren GI, Støttrup J, Ulmestrand M, Knutsen JA (2006) NOBANIS - Invasive alian species fact sheetHomarus americanus. ICES Council Meeting. Online database of the North European and Baltic network on invasive alien species. Available at: www.nobanis.org (accessed on 27 August 2007)

Williams AB (1995) Taxonomy and evolution. In: Factor JR (ed) Biology of the lobster Homarus americanus. Academic Press, New York, p 13-21

Submitted: September 4, 2007; Accepted: April 29, 2008

Proofs received from author(s): June 10, 2008 